\title{
Role of Social Media and Telemedicine in Diagnosis \& Management of COVID-19; An Experience of the Iranian Society of Radiology
}

Morteza Sanei Taheri, $\mathrm{MD}^{1 *}$; Farahnaz Falahati, $\mathrm{MD}^{2}$; Alireza Radpour, $\mathrm{MD}^{2}$; Vahid Karimi, $\mathrm{MD}^{2}$; Abdolrasoul Sedaghat, $\mathrm{MD}^{2}$; Mohammad Ali Karimi, $\mathbf{M D}^{2}$

'Department of Radiology, Shohada-E-Tajrish Hospital, Shahid Beheshti University of Medical Sciences, Tehran, Iran

${ }^{2}$ Iranian Society of Radiology, Tehran, Iran

\section{Dear Editor,}

Shortly following the diagnosis of the so-called COVID-19 on December, 31 in the first Chinese patient and its viral spread, Iran was one of the first countries to be stricken by the epidemic. ${ }^{1,2}$ The sudden emergence of the epidemic, the unknown nature of the disease and its viral spread quickly burdened the health care system of the country. ${ }^{3}$

Shortage of hospital beds for an overwhelming number of patients, low supply of diagnostic polymerase chain reaction kits, people's panic and the soaring number of cases among the health care personnel in low supply of protective gear further added to the complexity of the management challenge of the situation. ${ }^{4}$

Consequently, a reliable, safe and quickly available diagnostic tool turned out to be an essential element in controlling the spread of the virus. Reports indicating the potential of computed tomography (CT) scan to serve as a diagnostic tool with high sensitivity ${ }^{5,6}$ compelled the Iranian Society of Radiology (ISR) to form several teams to devise the regarding protocols for imaging of patients suspected of having the coronavirus and managing the utilization of web-based social networks to make diagnostic consultations available on a national basis.

The low dose CT protocol was proposed by the ISR to avoid the deleterious effects of high dose CT on patients. ${ }^{7}$ This method has played an important role in mitigating the burden of the disease by quick detection of new cases which results in timely management of the patients including implementation of isolation measures.

The ISR went on to establish an online panel of expert consultants known as the Iranian Society of Radiology COVID-19 Consultant Group (ISRCC) to devise a standard format of reporting CT scans of patients suspected of having the coronavirus ${ }^{7}$. Furthermore, by exploiting information technology (IT) and teleradiology, this panel of specialists has been constantly updating radiologists on a national basis as well as offering online consultations to physicians from all over the country on reporting CT scans and radiographs and even follow-up of patients which was hugely welcomed by physicians from even the neighboring countries.

In the first four days of launching this initiative, a second panel of 12 radiologists was formed due to the sheer number of requests and over 2000 consultation requests were addressed in three weeks.

For pregnant women who are suspected of COVID-19, a special protocol for imaging was devised and forwarded to all physicians.

To address the spread of the virus in diagnostic and treatment facilities and among health care personnel, a special and comprehensive guideline for protection of the people referring to health care facilities such as hospitals and their care providers was devised and announced through the net.

In general, the merits of online services include fast and continuous access as well as their interactive nature which are vital in quick initiation of treatment and in line with the principle of fair access. Nonetheless, application of the IT may depend on the quality and speed of the internet which at times have been a problem, yet we still believe that the IT and social media in particular, play a very important role in making fast decisions by the doctors and timely initiation of treatment and preventive measures. The results of this experience may also be conducive to addressing future challenges with screening and prevention of other diseases and situations where making prudent and timely decisions make a huge impact on mitigating burdens on health care systems, particularly in underdeveloped areas.

\section{Authors' Contribution}

MST Contributed to design of the study and planned the project.FF participated in the project and wrote the manuscript. AR contributed to the project, edited the manuscript. VK and AS contributed to the project and reviewed the manuscript. MAK contributed to the 
project, edited the manuscript. All authors have read and approved the content of the manuscript.

\section{Conflict of Interest Disclosures}

None.

\section{Ethical Statement}

Not applicable.

\section{References}

1. Wang C, Horby PW, Hayden FG, Gao GF. A novel coronavirus outbreak of global health concern. Lancet. 2020;395(10223):470-3. doi: 10.1016/S0140$6736(20) 30185-9$.

2. WHO. Novel Coronavirus-China. 2020. Available from: https://www.who.int/csr/don/12-january-2020-novelcoronavirus-china/en/. Accessed 25 March 2020.

3. WHO. Critical preparedness, readiness and response actions for COVID-19. Available from: https://www.who. int/publications-detail/critical-preparedness-readiness-andresponse-actions-for-covid-19. Accessed 19 March 2020.

4. Takian A, Raoofi A, Kazempour-Ardebili S. COVID-19 battle during the toughest sanctions against Iran. Lancet. March 18, 2020. doi: 10.1016/S0140-6736(20)30668-1.

5. Ai T, Yang Z, Hou H, Zhan C, Chen C, Lv W, et al. Correlation of chest CT and RT-PCR testing in coronavirus disease 2019 (COVID-19) in China: A report of 1014 cases. Radiology. 2020:200642. doi: 10.1148/radiol.2020200642.

6. Fang $\mathrm{Y}$, Zhang $\mathrm{H}$, Xie J, Lin $\mathrm{M}$, Ying L, Pang P, et al. Sensitivity of Chest CT for COVID-19: Comparison to RT-PCR. Radiology. 2020. doi: 10.1148/radiol.2020200432.

7. Mahdavi A, Khalili N, Davarpanah A H, Faghihi T, Mahdavi A, et al. Radiologic Management of COVID-19: Preliminary Experience of the Iranian Society of Radiology COVID-19 Consultant Group (ISRCC). Iran J Radiol. 2020. doi: 10.5812/ iranjradiol.102324.

Received: March 21, 2020, Accepted: March 22, 2020, ePublished: April 1, 2020

Cite this article as: Sanei Taheri M, Falahati F, Radpour A, Karimi V, Sedaghat A, Karimi MA. Role of social media and telemedicine in diagnosis \& management of COVID-19; Experience of the Iranian Society of Radiology. Arch Iran Med. 2020;23(4):285-286. doi: 10.34172/aim.2020.15.

(c) (1) (c) 2020 The Author(s). This is an open-access article distributed under the terms of the Creative Commons Attribution License (http://creativecommons. $\mathrm{org} /$ licenses/by/4.0), which permits unrestricted use, distribution, and reproduction in any medium, provided the original work is properly cited. 